\title{
Curing Characterization of Tannin-Hexamine Adhesive by Automated Bonding Evaluation System, Dielectric Analysis, and Dynamic Mechanical Analysis
}

\author{
Jaša Saražin, Bogdan Šega, and Milan Šernek * \\ The characterization of the curing process allows the determination of the \\ optimal pressing parameters, which is essential for the economical \\ production of wood-based composites. In this study, an automated \\ bonding evaluation system (ABES), dielectric analysis (DEA), and \\ dynamic mechanical analysis (DMA) were used to determine the curing \\ parameters of biobased pine tannin-hexamine adhesive at five \\ temperatures ranging from 75 to $175^{\circ} \mathrm{C}$. This study aimed to compare the \\ three above methods and to find correlations between them. All methods \\ showed the same trend of the curing process, which became faster with \\ increasing temperature. Due to various heating rates among the different \\ methods, the curves representing the degree of cure were shifted to the \\ left for the period in which nearly isothermal conditions were reached. It \\ was determined that these methods could be mutually comparable. The \\ $A B E S$ was regarded as the reference method; the DEA was regarded as \\ a method that overestimates the curing process and that describes the \\ beginning of the curing process more precisely; and the DMA method was \\ regarded as a method that underestimates the curing process and that \\ describes the end of the curing process more precisely. Linear trend lines \\ were found between the observed methods.
}

Keywords: Bio-based adhesive; Tannin; ABES; DEA; DMA; Rheometer; Curing characterization

Contact information: Department of Wood Science and Technology, Biotechnical Faculty, University of Ljubljana, 101 Jamnikarjeva, Ljubljana 1000 Slovenia; *Corresponding author: milan.sernek@bf.uni-lj.si

\section{INTRODUCTION}

The development of a new adhesive formulation and its successful application for bonding wood requires characterization of the curing process and determination of the final bond quality. Shear strength testing is commonly used to evaluate adhesive bond performance in solid wood (Derikvand and Pangh 2016). The bonding of several full-scale wood panels using various pressing parameters, followed by cutting them into test pieces, and testing the shear strength of adhesive bond according to the relevant standards is timeconsuming, expensive, and only useful for the fine-tuning of the pressing parameters. For this reason, several faster and more suitable methods have been developed to provide insight into the curing process of the wood adhesives (Ugovšek and Šernek 2013; Costa et al. 2014). Most of these methods are based on laboratory scale and measure various parameters that indirectly approximate the shear strength development of the adhesive.

The mechanical properties of the adhesive during curing can be examined by thermomechanical analysis (TMA), dynamic mechanical analysis (DMA), torsional braid analysis (TBA), integrated pressing and testing system (IPATES), and an automated bonding evaluation system (ABES). The analysis by TMA, DMA, and TBA measure changes of different moduli; IPATES and ABES, however, are the only two methods, that 
directly measure the adhesive bond strength during (or immediately after) pressing (Jošt and Šernek 2009; Šernek and Dunky 2010; Huang and Feng 2018; Solt et al. 2020).

The curing characterization of adhesives can also be predicted by measuring other parameters via infrared/Fourier transform infrared (IR and FTIR) spectroscopy, nuclear magnetic resonance (NMR), differential thermal analysis (DTA), differential scanning calorimetry (DSC), and dielectric analysis (DEA). The DEA method, for instance, measures the dielectric properties of the adhesive and is the only one of the listed methods that can perform continuous in situ measurements on a full-scale bonding process (Šernek and Dunky 2010; Ugovšek and Šernek 2013).

Since all the methods listed so far can be used to characterize the curing process of adhesives, the comparison between them and especially the correlation with methods that directly measure the shear strength of the adhesive is interesting for practice. Some authors have described the relationships between various methods, but the results are not consistent, which might be attributed to different studied adhesives and different research approaches, although some common conclusions regarding cited literature can be made. In two studies, DMA (bending and oscillatory tests) and DEA results expressed similar results on urea-formaldehyde adhesive and tannin foams (Pretschuh et al. 2012; Čop et al. 2015). The DEA, in comparison with ABES, was found to determine the curing process faster than ABES on phenol-formaldehyde adhesive. When the degree of cure evaluated from DEA was achieved at $90 \%$, the shear strength measured by ABES began to improve (Jošt and Šernek 2009). Comparisons between DSC and DMA methods mostly concluded that the chemical cure (DSC) starts before mechanical cure (DMA) and achieves the maximum degree of cure after the mechanical cure is already finished (Geimer and Christiansen 1996; Vazquez et al. 2005; Wang et al. 2011).

Because various curing characterization methods mostly differ between each other by different heating rates (before achieving isothermal conditions), measurements typically require tuning of temperature prior to comparison. However, some successful attempts that performed DMA and DEA measurements (Shepard and Twombly 1996; Pretschuh et al. 2012) or ABES and DEA measurements (Jošt and Šernek 2009) simultaneously on the same samples. Some methods (DSC and DMA) also allow setting the desired constant heating rates, from which the isothermal behavior could be recalculated with model-free kinetics (Wang et al. 2011).

Widely used synthetic adhesives containing formaldehyde are problematic due to environmental and health concerns. Formaldehyde emissions from wood panels can be reduced by producing new adhesives without formaldehyde or by modifying formaldehyde-based adhesives with scavengers (Costa et al. 2014). For this reason, biobased adhesives from natural sources have been attracting remarkable interest since the 1990s. Tannins are considered promising natural components for the replacement of synthetic adhesives due to their phenolic origin and their common natural occurrence (Pizzi 2016; Saražin et al. 2020b). It was determined that coniferous bark, as a by-product of the European wood industry, which is now mainly burned for energy, contains so much tannin that about $60 \%$ of the synthetic adhesives produced in Europe could be replaced (Saražin et al. 2020a). Researchers were successful with several formaldehyde-free adhesive formulations in which tannins are used as the main component. The most commonly used hardeners were hexamethylenetetramine (hexamine) (Pizzi and Tekely 1995; Pichelin et al. 1999; Pena et al. 2009), glyoxal, and furfuryl alcohol (Pizzi 2016; Gonultas 2018). 
One of the most promising formulations from that era is the pine/pecan tannin adhesive with a $6.5 \%$ addition of hexamine, which was also used industrially (Pizzi et al. 1997). A disadvantage of tannin-hexamine adhesives has been highly variable results, ranging from full exterior grade to poor interior grade wood panels (Pichelin et al. 1999).

Several studies have been performed to characterize the curing process on commercial synthetic adhesives, but only a few have been performed on bio-based adhesives. The reactivity of the mimosa tannin with different hardeners at various $\mathrm{pH}$ values was observed with NMR and FTIR (Tondi 2017) methods. The DMA-rheology was conducted on tannin formaldehyde adhesives (Garnier et al. 2002a, 2002b); and the TMA and ABES methods were performed on tannin hexamine adhesives (Lecourt et al. 2003). The DSC, TGA, and DMA curing characterizations were completed on tannin-based epoxy resin (Benyahya et al. 2014), and the curing characterization of tannin foams was studied with DEA, DSC, and DMA (Basso et al. 2013; Čop et al. 2015) methods. Modification of urea-formaldehyde adhesive with birch bark was investigated with DSC, TGA and DTG (Reh et al. 2021). Liquefied wood as an adhesive was studied with DEA, DSC, and DMA (Ugovšek and Šernek 2013) and lignin-based epoxy resin with DSC and TGA (Ferdosian et al. 2015). In the majority of those research studies, the comparison between different methods was not examined.

This research aimed to compare three methods (DMA, DEA, and ABES) for the determination of the curing process of bio-based pine tannin-hexamine adhesive and to find correlations between them. Such a correlation will be a useful tool for optimizing the pressing time in the wood-based composite industry.

\section{EXPERIMENTAL}

The curing process of the tannin-hexamine adhesive was observed using the DMA, DEA, and ABES methodologies. The results from these methods were compared at five different temperatures: $75,100,125,150$, and $175^{\circ} \mathrm{C}$.

\section{Materials}

\section{Tannin-hexamine adhesive preparation}

The tannin-hexamine adhesive mixture was prepared in three steps: (1) at first, $4 \mathrm{~g}$ of maritime pine (Pinus pinaster) tannin powder (Phenopin, DRT, France, 92\%-94\% polyphenolic content) were dissolved in $6 \mathrm{~g}$ of distilled water; (2) The $\mathrm{pH}$ value was then adjusted from 6.5 to 7.0 with $\mathrm{NaOH}$ (99\% pure sodium hydroxide, Fischer Scientific, UK) solution; and (3) About $0.6 \mathrm{~g}$ of $40 \%$ water solution of hexamine (99\% pure hexamethylenetetramine, Carlo Erba Reagents S.A.S., France) were added (as 6\% hexamine dry weight to the tannin dry weight). The density of the prepared adhesive was determined to be $1.04 \mathrm{~g} / \mathrm{cm}^{3}$.

\section{Veneer}

Sliced beech (Fagus sylvatica) veneers were used in two (i.e. ABES and DEA) of three methods performed. The $0.84 \mathrm{~mm}$ thick veneers were conditioned at $23{ }^{\circ} \mathrm{C}$ and $50 \%$ relative humidity before the tests were carried out. 


\section{Methods}

Automated bonding evaluation system

Adhesive bond strength was evaluated with ABES (Adhesive Evaluation Systems Inc., Oregon, USA), in accordance with the ASTM D7998-19 (2019) standard. The ABES method comprises of a combination of a small hot press and tensile-testing machine.

Sliced beech veneers, cut with the pneumatic cutter to a size of $117 \mathrm{~mm}$ x $20 \mathrm{~mm}$, were bonded in the hot press at five selected temperatures at various pressing times. The geometry of the bonded area of the veneer lap joints was $5 \mathrm{~mm} \times 20 \mathrm{~mm}\left(100 \mathrm{~mm}^{2}\right)$. However, the actual area of each tested sample was measured. The mass of the tested adhesive used was approximately $0.02 \mathrm{~g}$.

Various press times (10 to 12 for each of the five observed temperatures) ranging from $10 \mathrm{~s}$ to $600 \mathrm{~s}$ were chosen to study the bond shear strength development over time.

The actual temperature transition to the bond line during heating and cooling was observed with a K-type thermocouple at frequency of a $1 / \mathrm{s}$ for three samples at each of the five press temperatures.

After the opening of the hot press, the adhesive bond was cooled with compressed air for $5 \mathrm{~s}$. After the cooling step, all bonded specimens were tested in the temperature range between 40 and $60^{\circ} \mathrm{C}$.

The last step involves the testing of shear strength of the adhesive bond. The lap joint was pulled until the rupture occurred (approx. $11 \mathrm{~s}$ after the hot press opening). The maximum achieved force was compared with the bonded area, and the resulting shear strength $\left(\sigma_{t}\right)$ was expressed in $\mathrm{N} / \mathrm{mm}^{2}$.

The degree of cure was estimated following Eq. 1,

$$
\alpha(\mathrm{t})_{\mathrm{ABES}}=\frac{D f_{\mathrm{t}}}{\mathrm{Df}_{\max }}
$$

where $\sigma_{\max }$ is the maximum shear strength of all observed temperatures, and $\sigma_{\mathrm{t}}$ is shear strength during cure. After achieving the maximum degree of cure, the curves were flattened.

\section{Dielectric analysis}

The DEA measurements were carried out using a fringe field sensor (IDEX, Netzsch 066S, Selb, Germany). In all experiments, the IDEX sensor was positioned in the adhesive bond between the two sliced beech (Fagus sylvatica) veneers with a size of 100 $\mathrm{mm} \times 100 \mathrm{~mm}$, which was controlled by a precision LCR meter (Agilent, Type 4285A, Santa Clara, CA, USA) operating at the frequency of $100 \mathrm{kHz}$. The LCR meter measures the impedance (inductance, capacitance, and resistance) at spot frequencies. The temperature in the bond line between the veneers was recorded with a J-type thermocouple connected to a data acquisition switch unit (Agilent, Type 34970A, Santa Clara, CA, USA). Changes in the capacitance, loss tangent, conductance $(G)$, and the temperature $(T)$ were monitored with a frequency of $1.0 \mathrm{~Hz}$ up to $10 \mathrm{~min}$, during pressing with $0.8 \mathrm{MPa}$ load in a small laboratory hot press. Three replications were conducted for each set of measurements.

The degree of cure was estimated following Eq. 2 (Šernek and Kamke 2007),

$$
\alpha(\mathrm{t})_{\mathrm{DEA}}=\frac{\mathrm{G}_{\max }-\mathrm{G}_{\mathrm{t}}}{\mathrm{G}_{\max }-\mathrm{G}_{\min }}
$$

where $G_{\max }$ is the maximum conductance at each observed temperature, $G_{\mathrm{t}}$ is the conductance during cure, and $G_{\min }$ is the minimum conductance at each observed 
temperature. Since the curing process was not completed at all performed measurements, $G_{\min }$ was set to $10^{-5} \mathrm{~S}$ for all performed measurements. Before achieving the minimum degree of cure, and after achieving the maximum, the curves were flattened.

\section{Dynamic mechanical analysis}

The oscillatory tests in DMA were carried out on ARES G2 rheometer (TA Instruments, Delaware, USA). The adhesive was applied on disposable aluminium plates of $25 \mathrm{~mm}$ diameter. The parallel plate methodology was used with a gap of $0.5 \mathrm{~mm}$. The mass of the tested adhesive was approximately $2.5 \mathrm{~g}$. The sinusoidal oscillation frequency of the lower plate was $1.0 \mathrm{~Hz}$, with 0.007 peak strain. The target temperature of $75^{\circ} \mathrm{C}$ with a maximum heating rate of $60{ }^{\circ} \mathrm{C} / \mathrm{min}$ reached in $0.8 \mathrm{~min}$, and the target temperature of $175^{\circ} \mathrm{C}$ consequently in $2.5 \mathrm{~min}$. However, the real temperature in the rheometer oven was observed in situ.

The resulting storage modulus $G^{\prime}$, expressed in $\mathrm{MPa}$, was recalculated to the degree of cure $(\alpha(t))$, following Eq. 3 (Wang et al. 2011),

$$
\alpha(\mathrm{t})_{\mathrm{DMA}}=\frac{\mathrm{G}_{\mathrm{t}}^{\prime}-\mathrm{G}_{\text {min }}^{\prime}}{\mathrm{G}_{\text {max }}^{\prime}-\mathrm{G}_{\text {min }}^{\prime}}
$$

where $G^{\prime}{ }^{\prime} \min$ and $G^{\prime}{ }_{\max }$ represent the minimum and maximum storage shear modulus $G^{\prime}$ of all observed temperatures, respectively, and $G^{\prime}$ the value of the storage modulus at time $t$. Before achieving the minimum degree of cure, and after achieving the maximum, the curves were flattened.

\section{RESULTS AND DISCUSSION}

\section{Immediate Results}

The following figures show the average curves of original measurements and their recalculation in relation to the degree of cure for each method. The shear strength results of the ABES method were calculated as an average of six measurements (Fig. 1).
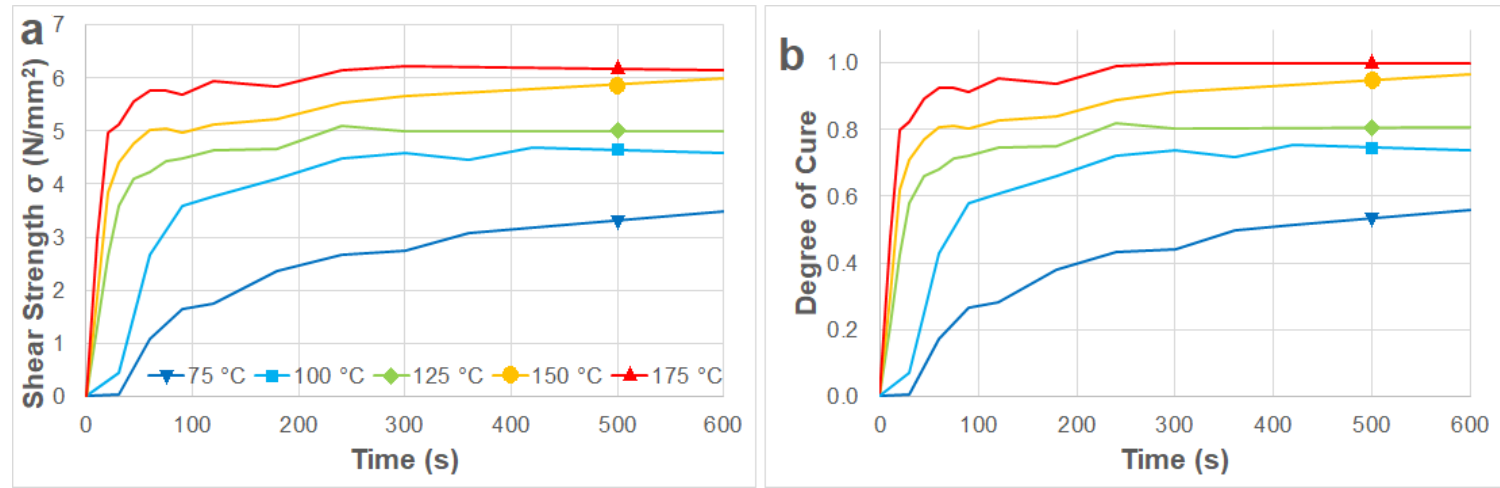

Fig. 1. Original results of shear strength measured by the ABES method (a) and recalculated results to the degree of cure (b)

The DEA curves were calculated as the average of three measurements (Fig. 2). For analysis above $100{ }^{\circ} \mathrm{C}$, the full cure of the adhesive (above $99.99 \%$ ) was determined, when conductance reached $10^{-5} \mathrm{~S}$. Because the curing process was not finished in the time of the 
performed experiment at temperatures of 75 and $100{ }^{\circ} \mathrm{C}$, it was assumed that conductance of potentially fully cured adhesive $\left(G_{\mathrm{min}}\right)$ would also be at those temperatures of $10^{-5} \mathrm{~S}$.
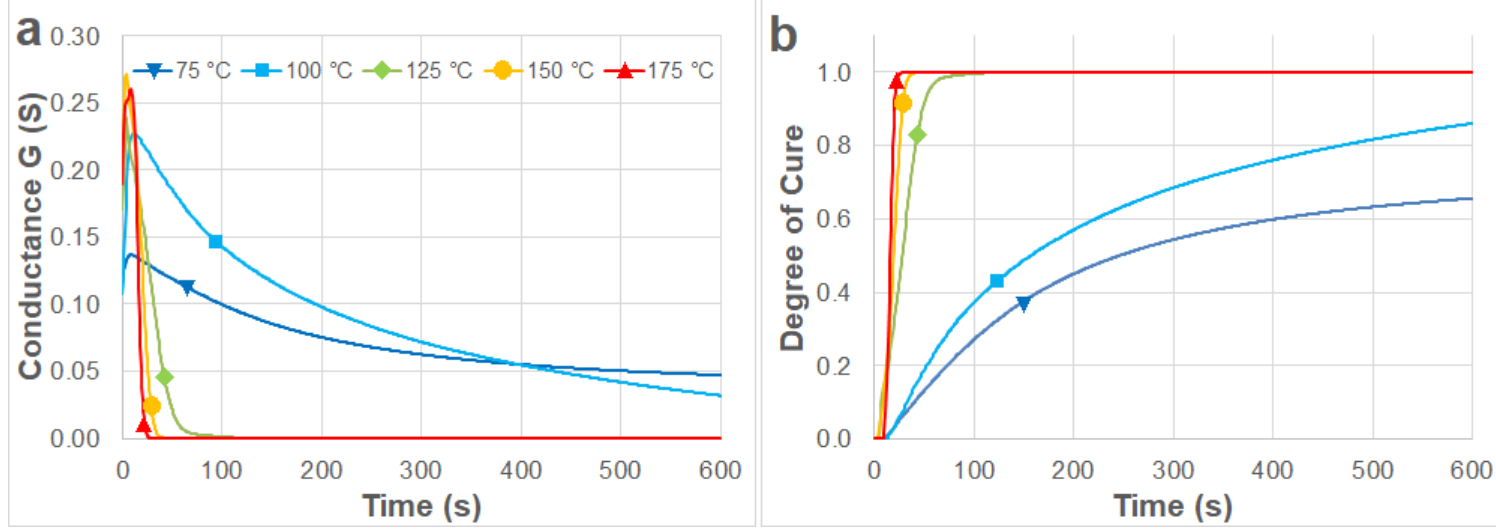

Fig. 2. Original results of the conductance measurements on the DEA (a) and recalculated results to the degree of cure (b) (Fig. 3).

The DMA curves were calculated as the average of at least three measurements
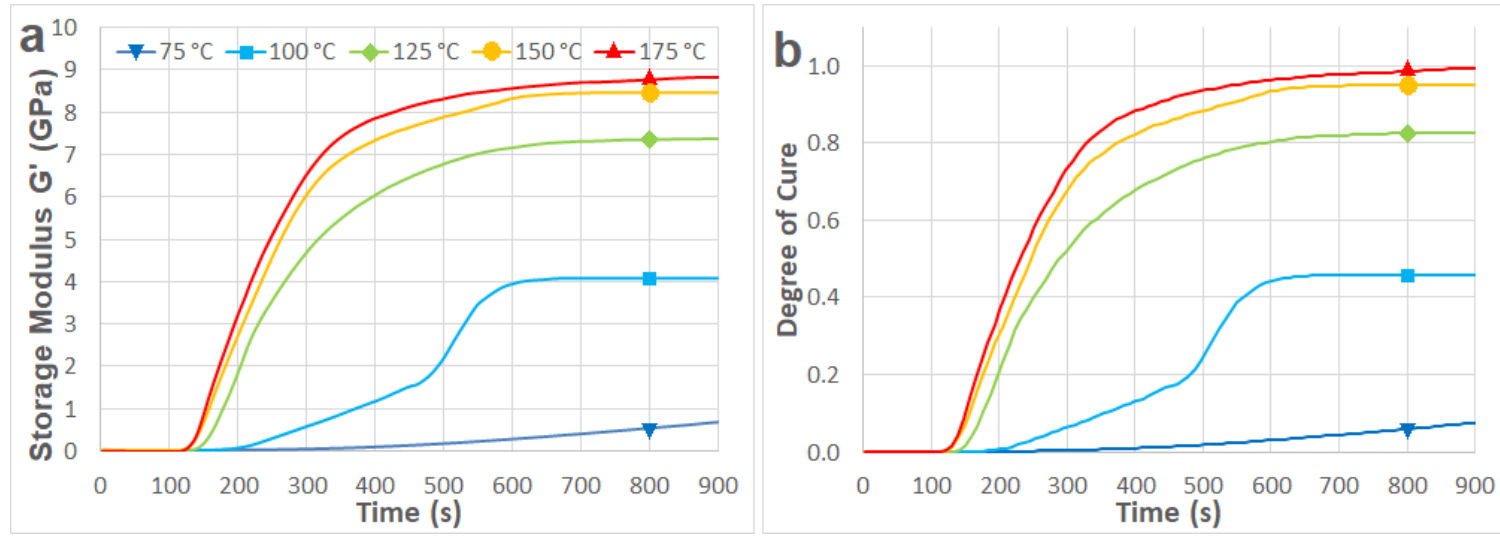

Fig. 3. Original results of storage modulus measurements on the DMA (a) and recalculated results to the degree of cure (b)

All methods showed the same trend of the curing process, becoming faster with increasing temperature. For a detailed comparison between various methods, the temperature transition to the tested adhesive and different methodologies would be taken into account, which was done in further steps.

\section{Temperature Transition to the Adhesive Bond}

The temperature transition to the adhesive bond differed between the curing characterization methods. The average results of three representative end temperatures (75, 125, and $175{ }^{\circ} \mathrm{C}$ ) are shown in Fig. 4. The differences between the ABES and DEA methods were negligible, $\pm 5{ }^{\circ} \mathrm{C}$ isothermal conditions took place between the first $0.1 \mathrm{~min}$ to $0.6 \mathrm{~min}$. However, DMA heating curves were much slower: $\pm 5{ }^{\circ} \mathrm{C}$ of the end temperatures were reached after $2.2 \mathrm{~min}$ to $3.8 \mathrm{~min}$. 


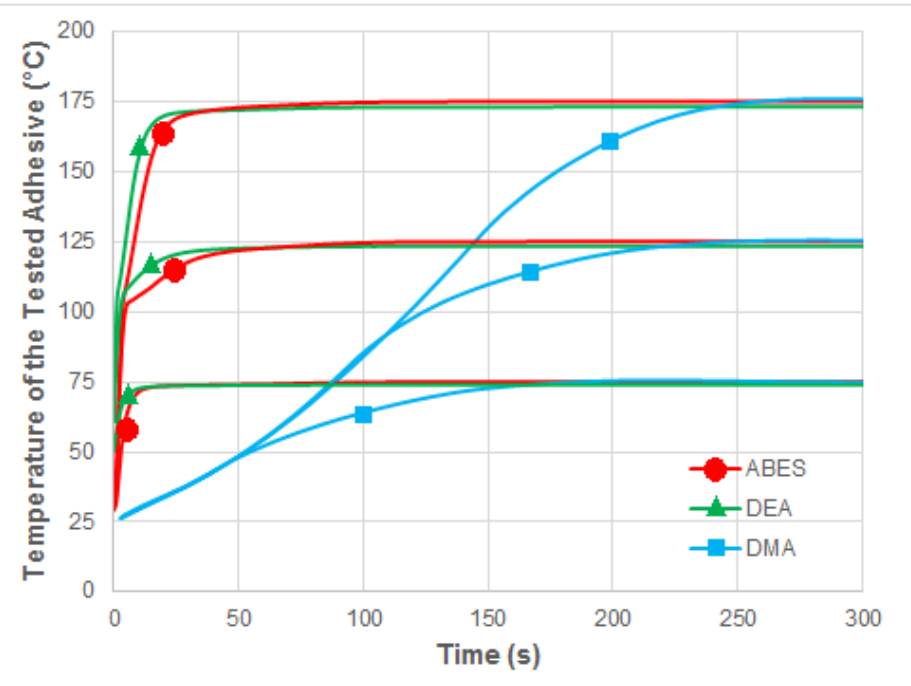

Fig. 4. Temperature transition to the adhesive bond

\section{Comparable (Shifted) Results}

For a more reliable comparison of the methods, all curves were shifted to the left, for the time, until $\pm 5{ }^{\circ} \mathrm{C}$ of the end temperature were reached. In this manner, only the isothermal conditions were taken into account. In Fig. 5, the curing processes observed by all three methods are presented for each observed temperature. Three curves of the same color present the average value with standard deviations.

After eliminating the effect of the various heating rates, the isothermal pressing schedule could be proposed. The DEA results defined the end of the curing process soon after achieving nearly isothermal conditions. Considering only the ABES and DMA curves, the proposed pressing time for $175^{\circ} \mathrm{C}$ would be around 5 and 10 min for $150{ }^{\circ} \mathrm{C}$. At 125 ${ }^{\circ} \mathrm{C}$, the studied adhesive approached close to a complete cure. Further studies would be required to assess whether a longer pressing time would result in a complete cure or the $80 \%$ degree of cure is the maximum that could be achieved at $125^{\circ} \mathrm{C}$.

The results of all three methods showed that bonding temperatures of 75 and 100 ${ }^{\circ} \mathrm{C}$ were not sufficient for bonding with the investigated tannin-hexamine adhesive, since curing at these temperatures did not result in complete cure in an economically justifiable pressing time.

Because the ABES method is measuring a bonding strength of the adhesive bond, it can be considered as a reference.

The applied DEA method was considered as a method that mostly overestimates the curing process, but it is quite accurate in the first part of the curing process (up to $80 \%$ degree of cure on ABES). This might be because conductance does not change that much once the polymer chains in the adhesive became longer.

However, the curing process observed by the DMA was considered to mostly underestimate the curing process (it is the slowest), but it is quite accurate in describing the end of the curing process (above 50\% degree of cure on ABES). This can be explained by (1) the higher amount of tested adhesive, which needs more time for heating and curing; (2) the absence of wood, which serves as a catalyst for the curing process and as a hydrophilic material for water absorbance; and (3) the absence of pressure, which allows better penetration into the wood. 

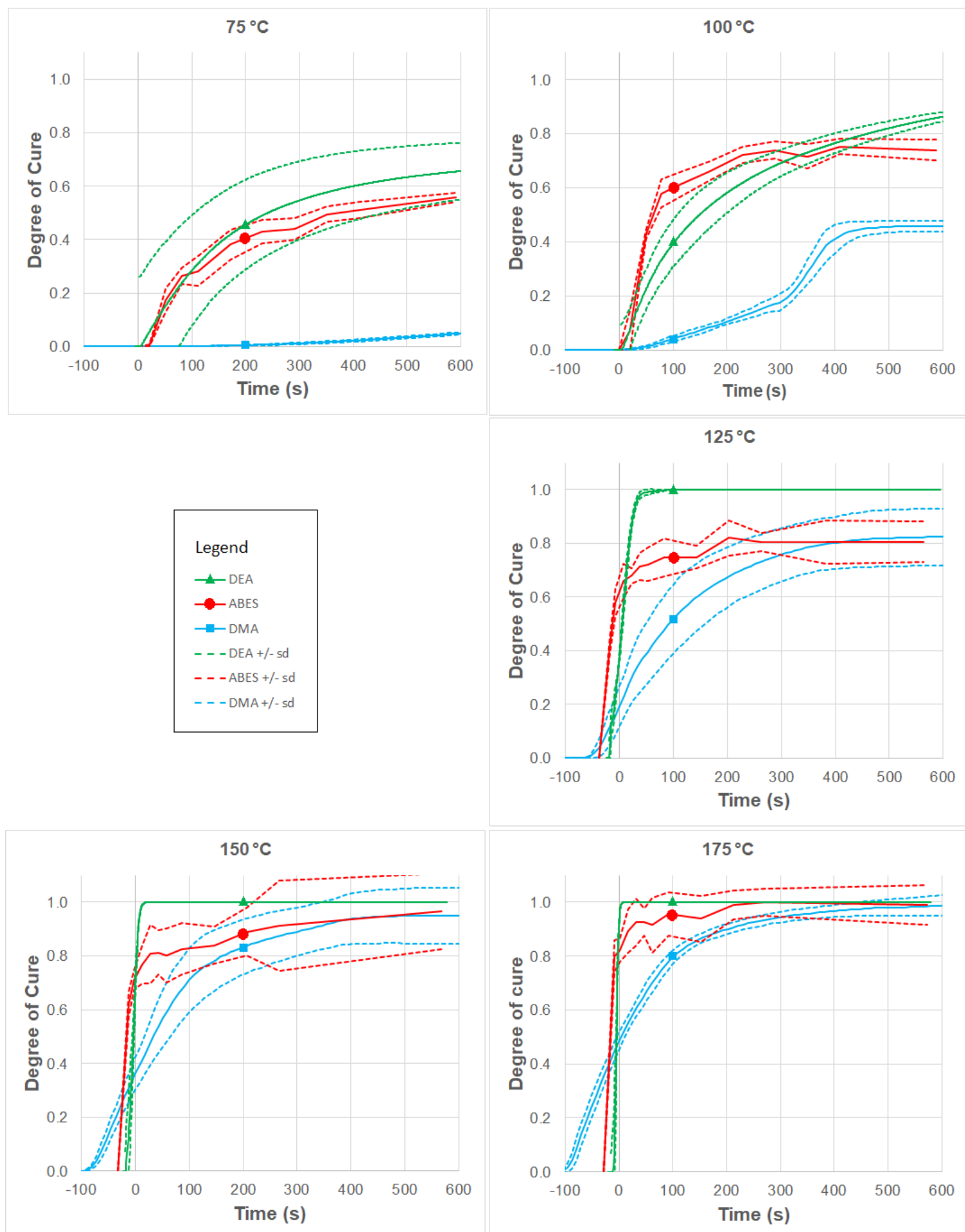

Fig. 5. Comparison of the degree of cure by ABES, DEA, and DMA methods for $75^{\circ} \mathrm{C}, 100^{\circ} \mathrm{C}$, $125^{\circ} \mathrm{C}, 150^{\circ} \mathrm{C}$, and $175^{\circ} \mathrm{C}$. All curves are shifted to the left, which is evident in "negative" times, so that isothermal conditions of $\pm 5^{\circ} \mathrm{C}$ are achieved. The solid line presents the average value, and the dotted lines present \pm standard deviation (sd) of all performed measurements. 


\section{Correlation between Methods}

The degree of cure observed by the ABES method was compared with the degree of cure observed by DEA and DMA (Fig. 6).
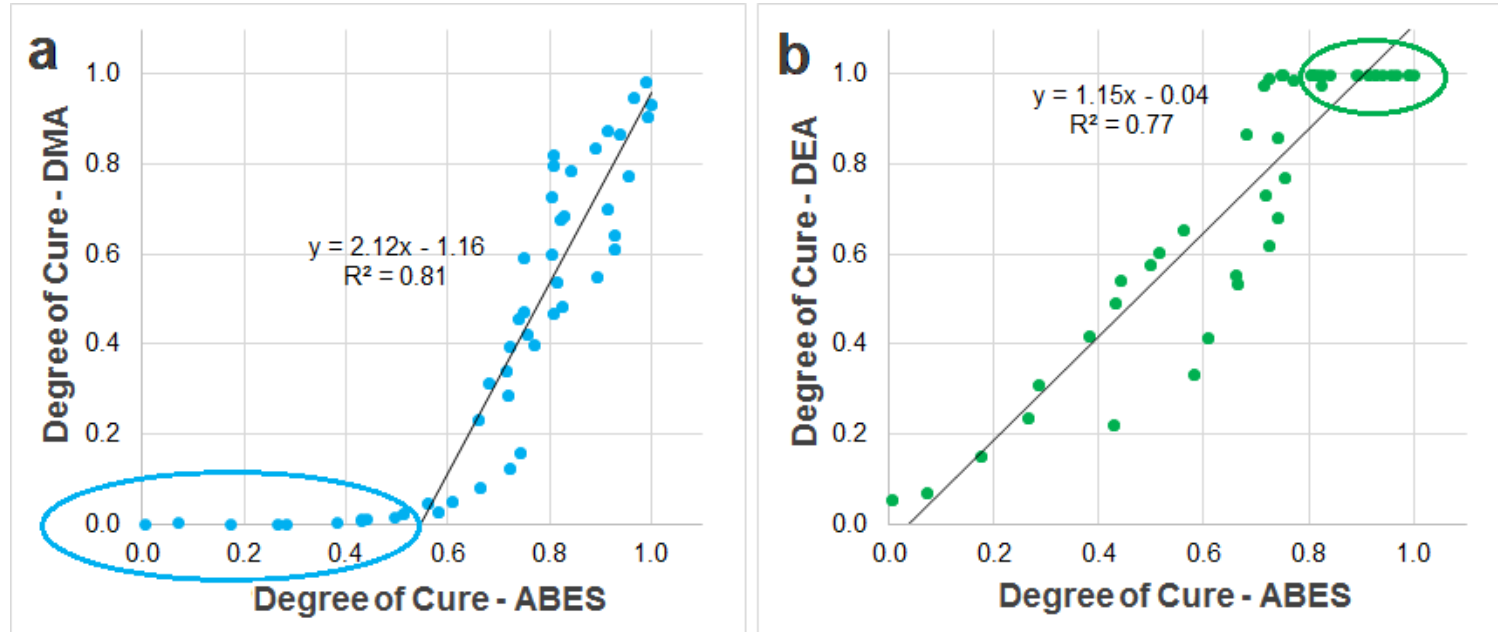

Fig. 6. Correlation between degree of cure measured on ABES with DMA (a) and DEA (b). Trend lines were calculated without consideration of points in ellipses

It was determined that the methods could be mutually comparable, although there are some major differences between them. In the first part of the curing process, when the ABES method already detects up to $50 \%$ of the final bond strength, the DMA method does not yet detect the start of the curing process (blue ellipse on Fig. 6; those results were not considered for trend line). In contrast, when the ABES method detects only around $80 \%$ of the final bond strength, the DEA method detects the end of the curing process (green ellipse on Fig. 6; those results were not considered for trend line).

There were no statistically significant trend lines between the observed methods. However, without considering two flat zones in the ellipses, the linear correlation, also shown in Fig. 6, can be proposed.

\section{CONCLUSIONS}

1. All performed methods (ABES, DEA, and DMA) showed that bonding temperatures of 75 and $100{ }^{\circ} \mathrm{C}$ were not suitable for bonding wood with the studied tannin-hexamine adhesive. At $125^{\circ} \mathrm{C}$, the studied adhesive approached close to a complete cure, whereas at $150{ }^{\circ} \mathrm{C}$ and $175^{\circ} \mathrm{C}$ the adhesive cured completely. The proposed pressing time, under isothermal conditions, would be approximately $5 \mathrm{~min}$ at $175^{\circ} \mathrm{C}$ and $10 \mathrm{~min}$ at $150{ }^{\circ} \mathrm{C}$.

2. The curing process observed by the ABES was measured as a reference method, as it measures the strength of the adhesive bond, which is most important in practice.

3. The curing process assessed by the DEA was considered to mostly overestimate the curing process, but it is quite accurate in the first part of the curing process.

4. The curing process observed by the DMA mostly underestimates the curing process, but it is quite accurate in describing the end of the curing process. 


\section{ACKNOWLEDGMENTS}

This research was financed by the ERA-CoBioTech project WooBAdh (Environmentally friendly bioadhesives from renewable resources) and by the Slovenian Ministry of Education, Science and Sport and the Slovenian Research Agency within the framework of the program P4-0015. Special thanks go to Dr. Mirko Kariž for support in rheological measurements and Toni Šauperl for help with ABES measurements.

\section{REFERENCES CITED}

ASTM D7998-19 (2019). "Standard test method for measuring the effect of temperature on the cohesive strength development of adhesives using lap shear bonds under tensile loading," ASTM International, West Conshohocken, PA, USA.

Benyahya, S., Aouf, C., Caillol, S., Boutevin, B., Pascault, J. P., and Fulcrand, H. (2014). "Functionalized green tea tannins as phenolic prepolymers for bio-based epoxy resins," Industrial Crops and Products 53, 296-307. DOI: 10.1016/j.indcrop.2013.12.045

Costa, N. A., Pereira, J., Ferra, J., Cruz, P., Martins, J., Magalhães, F. D., Mendes, A. and Carvalho, L. H. (2014). "Evaluation of bonding performance of amino polymers using ABES," The Journal of Adhesion 90(1), 80-88. DOI: 10.1080/00218464.2013.784693

Čop, M., Gospodarič, B., Kamppainen, K., Giovando, S., Laborie, M. P., Pizzi, A., and Šernek, M. (2015). "Characterization of the curing process of mixed pine and spruce tannin-based foams by different methods," European Polymer Journal 69, 29-37. DOI: 10.1016/j.eurpolymj.2015.05.020

Derikvand, M., and Pangh, H. (2016). "A modified method for shear strength measurement of adhesive bonds in solid wood," BioResources 11(1), 354-364. DOI: 10.15376/biores.11.1.354-364

Ferdosian, F., Yuan, Z., Anderson, M., and Xu, C. (2015). "Sustainable lignin-based epoxy resins cured with aromatic and aliphatic amine curing agents: Curing kinetics and thermal properties," Thermochimica Acta 618, 48-55. DOI: 10.1016/j.tca.2015.09.012

Garnier, S., Pizzi, A., Vorster, O. C., and Halasz, L. (2002a). "Rheology of polyflavonoid tannin-formaldehyde reactions before and after gelling. I. Methods," Journal of Applied Polymer Science 86(4), 852-863. DOI: 10.1002/app.10991

Garnier, S., Pizzi, A., Vorster, O. C., and Halasz, L. (2002b). "Rheology of polyflavonoid tannin-formaldehyde reactions before and after gelling. II. Hardener influence and comparison of different tannins," Journal of Applied Polymer Science 86(4), 864-871. DOI: 10.1002/app.10990

Geimer, R. L., and Christiansen, A. W. (1996). "Critical variables in the rapid cure and bonding of phenolic resins," Forest Products Journal 46(11/12), 67-27.

Gonultas, O. (2018). "Properties of pine bark tannin-based adhesive produced with various hardeners," BioResources 13(4), 9066-9078. DOI:10.15376/biores.13.4.90669078

Huang, Z., and Feng, M. (2018). "Correlation of adhesive performance between automated bond evaluation system tests and plywood tests: A case study of lignin- 
phenol-formaldehyde adhesives," Forest Products Journal 68(4), 353-358. DOI: 10.13073/FPJ-D-17-00064

Jošt, M., and Šernek, M. (2009). "Shear strength development of the phenolformaldehyde adhesive bond during cure," Wood Science and Technology 43, article no. 153. DOI: 10.1007/s00226-008-0217-2

Lecourt, M., Pizzi, A., and Humphrey, P. (2003). "Comparison of TMA and ABES as forecasting systems of wood bonding effectiveness," Holz als Roh- und Werkstoff 61, 75-76. DOI: $10.1007 / \mathrm{s} 00107-002-0346-5$

Pena, C., de la Caba, K., Retegi, A., Ocando, C., Labidi, J., Echeverria, J. M, and Mondragon, I. (2009). "Mimosa and chestnut tannin extracts reacted with hexamine in solution," Journal of Thermal Analysis and Calorimetry 96(2), 515-521. DOI: 10.1007/s10973-007-8352-9

Pichelin, F., Kamoun, C., and Pizzi, A. (1999). "Hexamine hardener behaviour: Effects on wood glueing, tannin and other wood adhesives," Holz als Roh-und Werkstoff 57 , 305-317. DOI: $10.1007 / \mathrm{s} 001070050349$

Pizzi, A. (2016). "Wood products and green chemistry," Annals of Forest Science 73, 185-203. DOI: 10.1007/s13595-014-0448-3

Pizzi, A., Stracke, P., and Trosa, A. (1997). "Industrial tannin/hexamine low-emission exterior particleboards," European Journal of Wood and Wood Products 55, 168. DOI: $10.1007 / \mathrm{BF} 02990538$

Pizzi, A., and Tekely, P. (1995). "Mechanism of polyphenolic tannin resin hardening by hexamethylenetetramine: CP-MAS 13C-NMR," Journal of Applied Polymer Science 56(12), 1645-1650.

Pretschuh, C., Müller, U., Wuzella, G., Dorner, F., and Eckmann, R. (2012). "Dielectric analysis as curing control for aminoplast resins - correlation with DMA," European Journal of Wood and Wood Products 70, 749-753. DOI: 10.1007/s00107-012-0612-0

Reh, R., Krišt’ák, L., Sedliačik, J., Bekhta, P., Božiková, M., Kunecová, D., Vozárová, V., Tudor, E. U., Antov, P., and Savov, V. (2021). "Utilization of birch bark as an eco-friendly filler in urea-formaldehyde adhesives for plywood manufacturing," Polymers 13, 511. DOI: 10.3390/polym13040511

Saražin, J., Potočnik, I., and Šernek, M. (2020a). "Tannin and lignin sources availability for the holistic replacement of synthetic wood adhesives in the European area," Gozdarski Vestnik (Ljubljana) 78(1), 23-30.

Saražin, J., Schmiedl, D., Pizzi, A., and Šernek, M. (2020b). "Bio-based adhesive mixtures of pine tannin and different types of lignins," BioResources 15(4), 94019412. DOI: 10.15376/biores.15.4.9401-9412

Solt, P., Libowitzky, S., van Herwijnen, H. W. G., and Konnerth, J. (2020). "Improved method for analyzing cohesive strength development of pMDI," Wood Science and Technology 54, 7-17. DOI: 10.1007/s00226-019-01143-7

Šernek, M., and Dunky, M. (2010). "Adhesive bond strength development," in WoodBased Panels: An Introduction for Specialists, H. Thoemen, M. Irle, and M. Sernek (eds.), Brunel University Press, London, UK, pp. 203-224.

Šernek, M., and Kamke, F. A. (2007). "Application of dielectric analysis for monitoring the cure process of phenol formaldehyde adhesive," International Journal of Adhesion and Adhesives 27(7), 562-567. DOI: 10.1016/j.ijadhadh.2006.10.004

Shepard, D. D., and Twombly, B. (1996). "Simultaneous dynamic mechanical analysis and dielectric analysis of polymers," Thermochimica Acta 272, 125-129. DOI: 10.1016/0040-6031(95)02622-3 
Tondi, G. (2017). "Tannin-based copolymer resins: Synthesis and characterization by solid state ${ }^{13} \mathrm{C}$ NMR and FT-IR spectroscopy," Polymers 9, article no. 223. DOI: 10.3390/polym9060223

Ugovšek, A., and Šernek, M. (2013). "Characterisation of the curing of liquefied wood by rheometry, DEA and DSC," Wood Science and Technology 47, 1099-1111. DOI: 10.1007/s00226-013-0565-4

Vazquez, G., Lopez-Suevos, F., Gonzalez-Alvarez, J., and Antorrena, G. (2005). “Curing process of phenol-urea-formaldehyde-tannin (PUFT) adhesives: Kinetic studies by DSC and DMA," Journal of Thermal Analysis and Calorimetry 82, 143-149. DOI: 10.1007/s10973-005-0855-7

Wang, J., Laborie, M. P. G., and Wolcott, M. P. (2011). "Correlation of mechanical and chemical cure development for phenol-formaldehyde resin bonded wood joints," Thermochimica Acta 513(1-2), 20-25. DOI: 10.1016/j.tca.2010.11.001

Article submitted: May 04, 2021; Peer review completed: July 11, 2021; Revised version received and accepted: July 21, 2021; Published: July 22, 2021.

DOI: $10.15376 /$ biores.16.3.6174-6185 